\title{
Questes
}

vestes Revue pluridisciplinaire d'études médiévales

$36 \mid 2017$

Faire de l'histoire au Moyen Âge

\section{Faire de l'histoire : conclusion}

François Wallerich, Pauline Bouchaud et Mélanie Fougre-Lévêque

\section{(2) OpenEdition}

\section{Journals}

\section{Édition électronique}

URL : http://journals.openedition.org/questes/4425

DOI : 10.4000/questes.4425

ISSN : 2109-9472

Éditeur

Les Amis de Questes

Édition imprimée

Date de publication : 20 juin 2017

Pagination : 129-130

ISSN : 2102-7188

\section{Référence électronique}

François Wallerich, Pauline Bouchaud et Mélanie Fougre-Lévêque, "Faire de l'histoire : conclusion », Questes [En ligne], 36 | 2017, mis en ligne le 02 juillet 2017, consulté le 25 septembre 2020. URL http://journals.openedition.org/questes/4425 ; DOI : https://doi.org/10.4000/questes.4425 


\section{Conclusion}

\section{Pauline BouChAUd, Mélanie Fougre-LEVEQUE et François WALLERICH}

École pratique des hautes études, Université Paris-Sorbonne et Université Paris-Nanterre

Les articles réunis dans ce bulletin ont permis d'entrevoir la diversité des profils d'historiens et des pratiques historiques au Moyen Âge.

Les différentes contributions ont tout d'abord mis en évidence l'intérêt d'analyser la matérialité des œuvres historiques. Celle-ci permet, comme l'a souligné Antoine Brix, d'appréhender non seulement la diffusion, mais aussi la réception de ces œuvres, d'établir quels sont leurs lectorats - qui peuvent être extrêmement divers - et de déterminer quelles étaient les pratiques de lecture au Moyen Âge. L'étude d'une œuvre historique en tant qu'objet matériel peut également permettre de cerner le profil d'un historien avec plus de finesse et nous renseigner sur sa culture historique. Ainsi, Jean de Haynin, qui s'apparente, tant par son profil sociologique que par sa pratique de l'histoire, au type de «l'historien-amateur » proposé par Bernard Guenée, s'avère cependant maîtriser parfaitement les techniques de l'écrit et être pleinement conscient de son auctorialité, comme l'a montré Anh Thy Nguyen. Cet exemple est révélateur de la fragilité de tout essai de typologie des profils d'historiens pour la 
période médiévale. Les articles de Thomas Ledru et Anh Thy Nguyen ${ }^{1}$ illustrent la diversité de ces profils et des pratiques historiques de l'époque, une diversité qui nécessite de nuancer et d'affiner les catégories proposées par les essais de synthèse.

Dresser une typologie des genres historiques au Moyen Âge n'est pas moins difficile. Si les frontières sont poreuses entre chroniques, histoires, mémoires ou encore livres de raison, elles ne le sont pas moins entre histoire et roman. À ce titre, l'étude de Justine Breton sur les œuvres de Geoffroy de Monmouth et de Wace montre bien toute la difficulté qu'il peut y avoir à faire le départ entre les deux. Plutôt que deux genres aux contours bien définis, se dégage l'impression d'un continuum entre histoire et roman, qui invite à ne pas penser les œuvres médiévales à l'aune des définitions contemporaines. En particulier, si l'usage du concept de «littérature » pour le Moyen Âge peut s'avérer commode, il ne va pas sans une part d'anachronisme, dans la mesure où il présuppose l'existence d'un champ littéraire autonome ${ }^{2}$. Justine Breton et Shanshan $\mathrm{Lu}$ ont analysé respectivement le passage de l'histoire au roman chez Wace et de l'histoire au théâtre chez Pierre Gringore, qui illustre les relations étroites qu'entretiennent souvent œuvres littéraires et œuvres historiques durant toute la période. Dans ce cadre, la collaboration entre historiens et spécialistes de la littérature prend tout son sens.

\footnotetext{
${ }^{1}$ Auxquels il faut ajouter celui de Maxime Fulconis, «Francesco Montemarte (v. 1345-1400), l'histoire familiale de la pointe de l'épée à celle de la plume », que l'on pourra lire dans la version électronique $\mathrm{du}$ bulletin sur http://questes.revues.org.

${ }^{2}$ Le caractère anachronique du concept de «littérature » appliqué à la période médiévale a été souligné plusieurs fois par Michel Zink. Pour ce dernier, il s'agit de mettre en garde contre une approche qui détacherait les textes littéraires du « domaine religieux » dans lequel ils s'inscrivent, notamment «en considérant la littérature comme un champ autonome (ce qui est anachronique) »: Michel Zink, Poésie et conversion au Moyen Âge, Paris, PUF, p. 3.
} 